\title{
Study of occupational lung cancer in asbestos factories in China
}

\author{
Zhu Huilan, Wang Zhiming
}

\begin{abstract}
A retrospective cohort study (1972-81) of occupational cancers in asbestos (chrysotile) factories has been previously published. In this paper the results of continued tracing and interviewing of members of this cohort from 1982 to 1986 is reported. The cohort included 5893 persons (45 974 person-years for men and 39445 person-years for women). Malignant tumours played a large part in causes of death (36.9\%). There were 183 cancers and 67 lung cancers among 496 deaths. The mortality due to lung cancer had a tendency to increase. By comparison with a control group, the $R R$ of lung cancer was 5.32 $(p<0 \cdot 01)$, and the SRR of lung cancer was 4.2 $(p<0.01)$, significantly higher than those of a control group. Among 148 cases of death from asbestosis there were 33 cases complicated with lung cancer $(22 \cdot 3 \%)$. The dose-response relations between exposure to asbestos and incidence of asbestosis and lung cancer were also studied in one asbestos factory. There was a positive correlation. A synergistic effect was found between cigarette smoking and lung cancer. Preventive and control measures and exposure limits for asbestos dust in the air of workplaces were recommended.
\end{abstract}

(British Fournal of Industrial Medicine 1993;50:1039-1042)

In 1987 we reported the mortality experience of a retrospective cohort (1 January 1972-31 December 1981) of asbestos factory workers in China. ${ }^{1}$ The results showed that the death rates from total malignant tumours and lung cancers were significantly higher than those of the control group. The report provided a scientific basis for the

Institute of Occupational Medicine, CAPM, 29 Nan Wei Road, Beijing, 100050, China

Zhu Huilan

West China University of Medicine

Wang Zhiming
Ministry of Health to amend the list of occupational diseases. On 1 January 1982, the cohort was enrolled for prospective observation. We continued tracing and interviewing up to 31 December 1986. This paper reports the results of this secondary investigation.

\section{Methods}

The original cohort less one factory (of nine) was traced. The workers who had retired or left the factories or died between 1 January 1972 and 31 December 1986 were included. The workers not exposed to asbestos were chosen as the control group. For all workers the following data were obtained from the records in the medical department of factories, from hospital case reports and trade union, or from the workers themselves and their family members. We collected: (1) occupational history; (2) smoking habit; (3) past occupational diseases; (4) family history of tumours; (5) date of birth, sex, duration of service, workshop, and type of work; (6) average dust concentration of workshop and workplace; (7) for workers who died of tumours, data obtained from their hospital case reports, pathology reports, chest $x$ ray films, and death certificates, as well as from their colleagues, relatives, and medical departments.

\section{Results}

A total of 5893 persons from eight asbestos factories who had worked there for more than 15 years were traced to 31 December 1986 . The rate of follow up was $97 \cdot 1 \%$. From the $496(8 \cdot 4 \%)$ who had died one hundred and eighty three cancers and 67 lung cancers (including two pleural mesotheliomas) were found.

When compared to similar results published five years ago, ${ }^{1}$ table 1 indicates that total death and mortality from total cancer and lung cancer have increased in those five years, especially for male workers. Mortality from total cancer increased from 239.9 to $311 \cdot 0 / 100000$, and lung cancer from $92 \cdot 5$ to $110 \cdot 9 / 100000$.

It is clear from the percentage of specific causes 
Table 1 Total deaths from cancer, and deaths from lung cancer among asbestos workers (per 100 000)

\begin{tabular}{|c|c|c|c|c|c|c|c|}
\hline \multirow[b]{2}{*}{ Sex } & \multirow[b]{2}{*}{ Person-years } & \multicolumn{2}{|c|}{ Total } & \multicolumn{2}{|c|}{ Total cancer } & \multicolumn{2}{|c|}{ Lung cancer } \\
\hline & & No & Mortality & No & Mortality & No & Mortality \\
\hline $\begin{array}{l}\text { Men } \\
\text { Women } \\
\text { Total }\end{array}$ & $\begin{array}{l}45974 \\
39445 \\
85419\end{array}$ & $\begin{array}{l}395 \\
101 \\
496\end{array}$ & $\begin{array}{l}859 \cdot 2 \\
256 \cdot 1 \\
580 \cdot 7\end{array}$ & $\begin{array}{r}143 \\
40 \\
183\end{array}$ & $\begin{array}{l}311 \cdot 0 \\
101 \cdot 4 \\
214 \cdot 2\end{array}$ & $\begin{array}{l}51 \\
16 \\
67\end{array}$ & $\begin{array}{r}110.9 \\
40.6 \\
78.4\end{array}$ \\
\hline
\end{tabular}

Table 2 Causes of death among asbestos workers

\begin{tabular}{lcrr}
\hline Causes of death & No of deaths & Mortality (per 100 000) & Percentage \\
\hline Cancer & 183 & $214 \cdot 2$ & $36 \cdot 9$ \\
Respiratory disease & 47 & $55 \cdot 0$ & $9 \cdot 5$ \\
Hypertensive disease & 16 & $18 \cdot 7$ & $3 \cdot 2$ \\
Ischaemic heart disease & 31 & $36 \cdot 3$ & $6 \cdot 3$ \\
Other cardiovascular diseases & 57 & $66 \cdot 7$ & $11 \cdot 5$ \\
Cerebrovascular disease & 47 & $55 \cdot 0$ & $9 \cdot 5$ \\
Digestive disease & 30 & $35 \cdot 1$ & $6 \cdot 0$ \\
Tuberculosis & 30 & $35 \cdot 1$ & $6 \cdot 0$ \\
Trauma, toxicosis, and accidents & 21 & $24 \cdot 6$ & $21 \cdot 1$ \\
Other causes & 18 & $18 \cdot 7$ & $3 \cdot 6$ \\
Unknown cause & 16 & & $3 \cdot 2$ \\
Total & 496 & & $100 \cdot 0$ \\
\hline
\end{tabular}

${ }^{\star}$ Included 29 cases of asbestosis.

of death (table 2) that cancers were still the major cause of death $(36 \cdot 9 \%)$. Other cardiovascular diseases $(70 \%$ of them were pulmonary heart disease) come second. The next were respiratory and cerebrovascular disease. Asbestosis remained as previously, rarely being classified as a cause of death because the patients often died due to complications, such as pulmonary heart disease and tuberculosis. The incidence of asbestosis from 1972 to 1986 was about $1 \%$. Among the 148 cases of death from asbestosis, there were 33 complicated with lung cancer(22.3\%). This rate was higher than that of previous investigations $(16 \%)$.

The total number of cancer deaths was 143 for men and 40 for women, and the mortality from lung cancer was $110.9 / 100000$ for men, $40 \cdot 6 / 100000$ for women. Lung cancer was the most prevalent cancer. Cancer of the liver $(60.9 / 100000)$ for men and cancer of the breasto $(15 \cdot 2 / 100000)$ for women were second. The mor tality from lung cancer in the control group waso $19 \cdot 4 / 100000$ for men, next to cancer of the liver? $(23 \cdot 7 / 100000)$. The mortality from lung cancer was only 3.4/100 000 for women (table 3).

The average latent period for lung cancer was 23.91 years (geometric mean (G) ) (23.41 for men, 25.57 for women), and $77.3 \%$ of lung cancer occurred between 20 and 30 years after first employment. The lower limit of $95 \%$ range of normal values was 14.3 (13.9 for men and 15.4 for women). The average onset of lung cancer was at the age of 56.6 ( 58.4 for men, 51.0 for women). In general the patients died within one year of diagnosis.

Table 3 Incidence of cancers

\begin{tabular}{|c|c|c|c|c|}
\hline \multirow[b]{2}{*}{ Category of cancer } & \multicolumn{2}{|l|}{ Men } & \multicolumn{2}{|c|}{ Women } \\
\hline & No & $\begin{array}{l}\text { Mortality } \\
\text { (per 100 000) }\end{array}$ & No & $\begin{array}{l}\text { Mortality } \\
\text { (per 100 000) }\end{array}$ \\
\hline Oesophagus & 13 & $28 \cdot 3$ & 1 & $2 \cdot 5$ \\
\hline Stomach & 26 & $56 \cdot 6$ & 2 & $5 \cdot 1$ \\
\hline Colon and rectum & 3 & 6.5 & 2 & $5 \cdot 1$ \\
\hline Liver & 28 & $60 \cdot 9$ & 2 & $5 \cdot 1$ \\
\hline Larynx & 1 & $2 \cdot 2$ & - & - \\
\hline Lung & 51 & 110.9 & 16 & $40 \cdot 6$ \\
\hline Bone and articular cartilage & 5 & $10 \cdot 9$ & - & - \\
\hline Breast & - & - & 6 & $15 \cdot 2$ \\
\hline Cancer of uterus and cervix uterus & - & - & 5 & $12 \cdot 7$ \\
\hline Penis & 1 & $2 \cdot 2$ & - & - \\
\hline Leukaemia & 1 & $2 \cdot 2$ & 1 & 2.5 \\
\hline Other malignant tumours & 14 & 30.5 & 5 & $12 \cdot 7$ \\
\hline Total & 143 & & & \\
\hline
\end{tabular}


Table 4 Relative risk and attributive risk of lung cancer

\begin{tabular}{lllllll}
\hline & Person-years & No of deaths & $\begin{array}{c}\text { Mortality } \\
\text { (per 100 000) }\end{array}$ & $R R$ & $A R$ & $p$ Value \\
\hline $\begin{array}{l}\text { Asbestos workers } \\
\text { Controls }\end{array}$ & 85419 & 67 & 78.4 & & & \\
\hline
\end{tabular}

Table 5 Standardised death rate

\begin{tabular}{|c|c|c|c|c|}
\hline & Observed & Expected & $S R R$ & p Value \\
\hline \multicolumn{5}{|c|}{ Total cancers: } \\
\hline A & $\begin{array}{l}183 \\
92\end{array}$ & $\begin{array}{l}405 \cdot 7 \\
149 \cdot 7\end{array}$ & $2 \cdot 7$ & $<0.01$ \\
\hline \multicolumn{5}{|c|}{ Cancer of lung: } \\
\hline $\begin{array}{l}\mathrm{A} \\
\mathrm{C}\end{array}$ & $\begin{array}{l}67 \\
18\end{array}$ & $\begin{array}{r}147 \cdot 6 \\
35 \cdot 1\end{array}$ & $4 \cdot 2$ & $<0.01$ \\
\hline \multicolumn{5}{|c|}{ Cancer of stomach and intestine: } \\
\hline$\stackrel{\mathrm{A}}{\mathrm{C}}$ & $\begin{array}{l}46 \\
35\end{array}$ & $\begin{array}{l}99 \cdot 9 \\
64 \cdot 3\end{array}$ & $1 \cdot 6$ & $>0.05$ \\
\hline \multicolumn{5}{|c|}{ Cancer of stomach: } \\
\hline A & 28 & $61 \cdot 3$ & & \\
\hline C & 14 & $25 \cdot 3$ & $2 \cdot 4$ & $<0.01$ \\
\hline
\end{tabular}

$\mathrm{A}=$ asbestos workers; $\mathrm{C}=$ controls.

The relative risk (RR) and attributive risk (AR) of lung cancer in eight factories were significantly higher than in the control group. Total $R R$ was $5 \cdot 3(95 \%$ CI $2 \cdot 6-7 \cdot 1)$ and AR was 63.6 (p $<0.01$ table 4). Compared with the control group by sex, the $R R$ was 5.8 for men and 11.7 for women $(p<$ 0.01 ). The standardised relative risks (SRRs) of cancers and lung cancer were 2.7 and $4.2(\mathrm{p}<$ 0.01 ; table 5$)$. The SRR $(2.4, p<0.05)$ of cancer of the stomach was significantly higher than the control group.

The average duration of service of patients with lung cancer was 18.5 years $(G)(18.0$ for men and 11.5 for women), counted from the time of first exposure. The lower limit of the $95 \%$ range of normal values was $8.5(7.8$ for men and 11.5 for women). From the frequency distribution of service, the onset of lung cancer was mostly more than 10 years.

Table 6 Relation between asbestos exposure, smoking, and lung cancer

\begin{tabular}{llccr}
\hline Exposure & Smoking & Cases & $\begin{array}{l}\text { Total } \\
\text { person-years }\end{array}$ & \multicolumn{1}{c}{$R R$} \\
\hline No & No & 4 & 42502 & $1 \cdot 0$ \\
No & Yes & 11 & 63714 & 1.8 \\
Yes & No & 15 & 42218 & 3.8 \\
Yes & Light & 4 & 3812 & 11.3 \\
& Medium & 11 & 8689 & 13.7 \\
& Heavy & 12 & 13432 & $17 \cdot 8$ \\
\hline
\end{tabular}

Light, <half a pack a day; Medium, >half a pack a day; Heavy, $>$ one pack a day.
The onset of lung cancer was related to the type of work. The incidence of workers who treated crude material was the highest $(193 \cdot 8 / 100000)$, the next was for handling $(144 \cdot 8 / 100000)$, and twisting (79.2/100 000) was the next. The incidence for repairing and maintaining was not much lower. The concentration of dust of the crude material in the workshops was very high.

Table 6 indicates that smoking alone increased the $R R$ of lung cancer to 1.8 and asbestos exposure alone increased the $R R$ to $3 \cdot 8$. It means that the risk of lung cancer produced by asbestos exposure is twice as high that produced by smoking. Asbestos exposure and smoking in combination increased the $R R$ to $11 \cdot 3,13 \cdot 7,17 \cdot 8$ according to light, medium, and heavy smoking respectively.

\section{Discussion}

The results of this cohort show that total deaths, total deaths from cancer, and deaths from lung cancer were increased over those in the previous investigation five years ago, especially in male workers. ${ }^{1}$ Cancer was still the major cause of death and lung cancer remained the major cause of excess death. The RR $(5 \cdot 3(95 \%$ CI $2 \cdot 5-7 \cdot 1))$ of lung cancer was significantly higher $(p<0.01)$ than that of the control group. This is similar to other reports. ${ }^{23}$ Selikoff indicated that the period of latency between onset of exposure and death in lung cancer was $25-35$ years. ${ }^{4}$ In our study, the average latent period of lung cancer was 23.91 years $(G)$ ( 23.41 for men, 25.57 for women). Large increases in lung cancer occurred 20-35 years from first employment.

The incidence of asbestosis among asbestos workers between 1972 and 1981 was $1 \%$. Among 148 cases of death from asbestosis there were 33 cases complicated with lung cancer (22.3\%). Doll found 11 deaths from lung cancer associated with asbestosis ${ }^{5}$ : lung cancer in asbestos workers in the United Kingdom was made a prescribed disease when it was accompanied by asbestosis. ${ }^{6}$ We also considered this problem in China and suggested that it should be recognised as an occupational disease and covered by labour insurance.

Our results show a positive dose-response relation between exposure to asbestos and incidence of asbestosis and lung cancer. ${ }^{7}$ It is clear that asbestos 
dust must be controlled and the working time should be shortened for asbestos workers. According to these results we shall be recommending new health standards for asbestos dust in the air of the workplace.

A synergistic effect was also found between cigarette smoking and lung cancer among asbestos workers, so we must educate the workers who are exposed to asbestos and let them know the serious health risk caused by a combination of smoking and exposure. Smoking in the workplace should be forbidden.

The observations have been maintained from 1981 , in cooperation with another 11 unitsnamely, the Institute of Prevention and Treatment of Occupational Diseases of Tian jin Municipality; Tian jin Medical College; Sanitary and Antiepidemic Station of Chao yang district of Beijing; The Second Hospital of Chang cun Municipality; Institute of Occupational Medicine of Shen yang Municipality; Institute of Prevention and Treatment of Occupational Diseases of $\mathrm{Mu}$ dan jing Municipality; Institute of Prevention and Treatment of Occupational Diseases of $\mathrm{He}$ nan Province; Sanitary and Antiepidemic Station of Qing dao Municipality; and the asbestos factories of Beijing, Shen yang, and Chong qing.

1 Zhu Huilan, Wang Zhiming. A retrospective cohort study on occupational tumors in asbestos manufactories. Chinese Fournal of Industrial Hygiene and Occupational Diseases 1987;5:29-32.

2 Enterline PE. Estimating health risks in studies of the health effects of asbestos. Am Rev Resp Dis 1976;113:175.

3 McDonald JC. Asbestos and lung cancer: has the case been proven? Chest 1980;78:374-5.

4 Selikoff IJ. Latency of asbestos disease among insulation workers in the United States and Canada. Cancer 1980;46:2736-4.

5 Doll $\mathrm{R}$. Mortality from lung cancer in asbestos workers. $\mathrm{Br} \mathcal{F}$ Ind Med 1955;12:81-6.

6 Browne $\mathrm{K}$. Is asbestos or asbestosis the cause of the increased risk of lung cancer in asbestos workers? [editorial] $\mathrm{Br} \mathcal{F}$ Ind Med 1986;43:145-9.

$7 \mathrm{Zhu}$ Huilan, Yang Guichun. Dose-Response relationship between asbestos exposure and incidence of lung cancer. Industrial Health and Occupational Diseases 1991;17:337.

Accepted 11 January 1993

\section{Destruction of manuscripts}

From 1 July 1985 articles submitted for publication will not be returned. Authors whose papers are rejected will be advised of the decision and the manuscripts will be kept under security for three months to deal with any inquiries and then destroyed. 